\title{
ETNODESIGN: PRESERVAÇÃO E VALORIZAÇÃO DAS CULTURAS INDÍGENAS
}

\author{
Paula Cristina Pereira Silva \\ Universidade do Estado de Minas Gerais (UEMG) \\ designgobetti@gmail.com \\ Sérgio Antônio Silva \\ Universidade Federal de Minas Gerais (UFMG) \\ sergio.antonio74@hotmail.com
}

Resumo: $O$ presente artigo tem como objetivo abordar as relações estabelecidas entre a escrita alfabética e os povos indígenas do Brasil, a fim de compreender o surgimento da chamada nova escrita indígena, que vem demandando por novas metodologias de trabalho dos não indígenas envolvidos no seu processo de criação. Além disso, destaca-se, para os designers inseridos nesse novo cenário da escrita indígena, o etnodesign como uma ferramenta de pesquisa capaz de colaborar na preservação e valorização de elementos e características culturais, de natureza material e imaterial. Deste modo, inicialmente, realizou-se uma abordagem acerca de como essa escrita foi apresentada aos indígenas do Brasil e quais foram às primeiras percepções desses povos de tradição oral sobre essa ferramenta. Em seguida, fez-se uma análise sobre o primeiro papel assumido pela escrita na fase colonial - um dispositivo de controle, e, por seguinte, sobre o processo de ressignificação dessa ferramenta no final do século XX - um instrumento de defesa cultural. Isto posto, investigou-se a nova escrita indígena, resultado da ressignificação desse dispositivo pelos indígenas, que nasce de e para a nova escola indígena, sendo fomentada pela necessidade de reescrever uma história. Seguidamente, buscou-se compreender as peculiaridades culturais do processo de desenvolvimento dos impressos indígenas, suportes para a nova escrita indígena, que vem demandando dos não indígenas envolvidos metodologias de trabalho diferenciadas. Por fim, abordou-se o etnodesign como uma interessante metodologia de trabalho para os designers inseridos na produção dessa nova escrita indígena. Isto, devido ao fato do etnodesign ser um instrumento de pesquisa capaz de permitir a valorização e revitalização dos saberes indígenas, de contribuir com a consolidação da identidade nacional e a construção do design brasileiro.

Palavras-chave: escrita indígena, identidade cultural, design, etnodesign.

Abstract: This article aims to address the relations between alphabetic writing and the indigenous peoples of Brazil, in order to understand the emergence of the called new indigenous writing, which is demanding for new methods of work of non indigenous involved in its creation process. In 
addition, it stands out, for the designers included in this new scenario of indigenous writing, the etnodesign as a research tool that can assist in the preservation and enhancement of elements and characteristics cultural, of material and immaterial nature. Thus, initially, was done an approach about how this writing was presented to the indigenous people of Brazil and what were the first perceptions of these people of oral tradition had on this tool. Then, there was an analysis of the first role played by writing in the colonial phase - a control device, and, following on, the reframing process of this tool in the late twentieth century - a cultural instrument of defense. Thus, there was an investigation into the new indigenous writing, the result of the resignification of this device by the indigenous, which is born from and to an new indigenous school, being encouraged by the need to rewrite a story. Next, we sought to understand the cultural peculiarities of the development process of the indigenous printed, Next, we sought to understand the cultural peculiarities of the development process of the indigenous printed, supports for the new indigenous writing, demanding of the no indigenous involved in these creations different work methodologies. Lastly, was approached the etnodesign as an interesting work methodology for designers which already participate in the production of this new indigenous writing. This, due to the fact the etnodesign be a research tool to enable to recovery and revitalization of indigenous knowledge, contribute to the consolidation of national identity and the construction of brazilian design.

Keywords: indigenous writing, cultural identity, design, etnodesign.

\section{INTRODUÇÃO}

Os povos indígenas do Brasil apresentam-se hoje como um dos segmentos da sociedade brasileira que luta com maior intensidade pelo acesso a escola pública, as lideranças indígenas têm clareza da importância estratégica da educação escolar para seus povos, em particular para a sua juventude, uma porta para um futuro promissor. Além disso, nas últimas décadas, tem surgido um grande interesse, por parte dos povos indígenas, em revitalizarem suas línguas. Entretanto, esse cenário nem sempre foi assim. Ao longo de muitos anos a escrita e a alfabetização foram utilizadas pelos não indígenas como dispositivos de controle sobre os nativos.

O linguista Rodrigues (1986), especializado nos povos nativos do Brasil, afirma que em 1500 havia no Brasil em torno de 1.175 línguas indígenas distribuídas ao longo do território brasileiro e 1477 etnias. Hoje, segundo o IBGE (2016), das 305 etnias indígenas que resistiram ao longo do processo da colonização brasileira, até então, foram classificadas cerca de 274 línguas faladas. Percebe-se, assim, que a colonização impôs a cultura europeia de maneira repressiva para os povos indígenas. A Lei Pombalina, de 1758, criada para reforçar o projeto político que propunha apenas uma língua oficial para o país, a língua portuguesa, é uma prova disso. Essa lei abriu caminho para o fortalecimento da língua portuguesa, tornando-a obrigatória para os documentos oficiais e para implementação do ensino. Desde então, foi inaugurada 
uma política que tinha como objetivo "integrar" os povos indígenas à comunidade nacional, sem respeito algum à diversidade sociocultural e linguística existente. Como consequência direta dessa política, ocorreu o enfraquecimento do uso das línguas nativas entre muitos povos e o desprestígio dessas línguas diante da sociedade hegemônica, com a consequente negação das identidades e das culturas indígenas.

Isto posto, o presente artigo tem como objetivo abordar as relações estabelecidas entre a escrita alfabética e os povos indígenas do Brasil, a fim de compreender o surgimento da chamada nova escrita indígena, que nasce com os livros didáticos e demanda por novas metodologias de trabalho dos não indígenas, de diversas áreas (pedagogos, antropólogos, linguistas, designers, sociólogos), envolvidos no seu processo de criação. Para isso, inicialmente, abordou-se a chegada da escrita alfabética no Brasil, dando foco em como se deu o contato dos indígenas com esse instrumento que trazia consigo muitos interesses por parte do colonizador. Neste momento, utiliza-se como referência o livro A Conquista da Escrita, de Emiri; Monserrat (1989), para abordar as percepções dos indígenas nos primeiros contatos com a escrita, que perpassam pelo receio e pela sedução.

Por seguinte, baseado nos relatos do antropólogo Melià (1979), há uma abordagem sobre o primeiro papel que a escrita assumiu diante dos indígenas, o de dispositivo de controle. A atuação da escrita para o controle fica ainda mais clara quando se vincula à educação, à instituição escola nas aldeias formaliza a entrada do Estado nessa relação de dominação e opressão. Entretanto, com o passar do tempo, as denúncias internacionais e nacionais sobre o genocídio indígena no Brasil estimularam, como um ato de resistência, uma nova postura por parte dos nativos, não esperada pelo governo, a apropriação da escrita como um instrumento de defesa cultural. Este novo cenário, segundo Luciano (2006), foi intensificado pela Constituição de 1988, que revolucionou o rumo da educação indígena, estimulou o surgimento de uma nova escrita indígena. A chamada nova escrita indígena é o resultado da ressignificação desse veículo de comunicação pelos indígenas, nasce de e para a nova escola indígena, sendo fomentada pela necessidade de arrancar o poder de voz das mãos dos dominadores. Nasce na forma de livro didático, escrito, na maioria das vezes coletivamente por grupos de professores indígenas em cursos de formação de professores para as escolas indígenas.

Percebe-se assim, que essa nova escrita indígena estimulou o surgimento dos impressos nativos, que hoje são tanto os materiais que fazem a transição do âmbito da oralidade para o âmbito da escrita das histórias, cantos, mitos e poesias, conhecidos como "livros da floresta" (ALMEIDA; QUEIROZ, 2004), como os materiais didáticos para alfabetização diferenciada das etnias indígenas do Brasil. Como esses impressos são a materialização de uma tradução intersemiótica, que segundo Plaza (2003) é a interpretação de um sistema de signos para outro, neste caso, a tradução de um sistema de comunicação verbal para o não verbal, um caminho complexo (LIMA, 2012), repleto de tensões e, por isso, que demanda por metodologias de trabalho diferentes das que já são convencionalmente utilizadas. Diante disso, e do fato de que o designer ao longo do processo de desenvolvimento dos impressos indígenas atua não apenas como o executor de layout (LIMA, 2012), mas também como um tradutor cultural, finaliza-se este artigo com uma abordagem sobre o etnodesign. Uma ferramenta capaz de auxiliar os trabalhos e pesquisas com etnias indígenas, com grande potencial de contribuir com a preservação e valorização de elementos e 
aspetos culturais, de natureza material e imaterial, desses povos. Neste momento, utiliza-se como referencial teórico a dissertação de Nogueira (2005), Etnodesign: um estudo do grafismo das cestarias dos M'byá Guarani de Paraty-Mirim (RJ), e a tese de Cavalcante (2012), Design para a sustentabilidade cultural: recursos estruturantes para sistema habilitante de revitalização de conhecimento local e indígena.

\section{A ESCRITA INDIGENA NO BRASIL}

A escrita começou a fazer parte da vida dos indígenas do Brasil logo após o contato com os europeus, junto ao início do processo de colonização. Entretanto, segundo Martins (2009), a educação formal no Brasil iniciou-se apenas em 1549 com a Companhia de Jesus. Os jesuítas, assim, foram os primeiros mestres do Brasil, onde fundaram as primeiras missões, no interior do país. Nessas missões, os indígenas, além de passarem pela metodologia de catequização, eram norteados ao trabalho agrícola, o que garantia aos catequizadores uma de suas fontes de renda. O objetivo da educação formal nessa fase inicial era, especialmente, o de "civilização" e catequização dos índios e negros e a instrução dos descendentes dos colonizadores.

A produção de escritas para as línguas indígenas só ganhou força em $1956 \mathrm{com}$ a chegada do Summer Institute of Linguistics (SIL), missão cristã-evangélica criada no México em 1930, que realizou inúmeros convênios com o Estado brasileiro a fim de atuar com pesquisas e acessórias de ensino na área de linguística para os povos indígenas. O SIL estabeleceu-se em diversas cidades do norte do Brasil, produzindo conhecimento científico sobre as línguas indígenas. Em 1967 trabalhavam no Brasil trezentos membros do $S I L$, pesquisando quarenta línguas indígenas, sobre as quais realizou grande número de publicações, especialmente descrições gramaticais e cartilhas, diretamente adotadas em muitas escolas indígenas. É importante pontuar que mesmo o SIL contribuindo expressivamente para a preservação das línguas indígenas, ao tentarem atingir o seu objetivo principal, a evangelização por meio da tradução do Novo Testamento para sociedades sem escrita, acabavam por destituir vários aspectos das culturas nativas.

Com relação à percepção dos povos indígenas sobre a escrita, Emiri; Monserrat (1989) pontuam que fatos históricos e experiências etnográficas mostram que os índios oscilavam entre o receio e a sedução. O antropólogo Melià (1968, p. 271) cita que em 1614 os Guarani já desconfiavam seriamente daqueles recém-chegados que passavam um bom tempo a ler seus livros de reza, "diziam que éramos espiões e que nos livros trazíamos a morte". Entretanto, o mesmo antropólogo pontua que os indígenas ficavam encantados ao perceberem que com essa ferramenta o não indígena dominava uma espécie de magia, capaz de ir além do espaço e do tempo, referiam-se à capacidade da escrita de armazenar conteúdos de diferentes épocas e lugares. Segundo Emiri; Monserrat (1989), um dos indígenas Aruák do rio Juruena-Camararé, ao escutar a leitura de um mito do seu povo por um pesquisador, pensou que o livro estivesse falando e, assim, levou-o ao ouvido. O receio tornava-se, às vezes, uma fascinação mágica por possuir um instrumento que estaria na mesma base do conhecimento e poder do branco.

\subsection{Escrita: um dispositivo de controle}

Difunde-se cada vez mais a impressão de que a passagem das línguas orais para as línguas escritas foi marcada pela dominação. O livro $A$ conquista da escrita, Emiri; 
Monserrat (1989) confirmam essa impressão ao afirmarem que das inúmeras formas que os povos indígenas foram conquistados, a escrita também foi uma delas. $O$ desejo de entender a língua do outro por parte do conquistador trazia embutida a vontade de ser entendido, e o que devia ser entendido naquele momento era a mensagem do cristianismo. Assim, os jesuítas dos séculos XVI e XVII parecem ter dado as regras que os linguistas e educadores envolvidos na alfabetização reproduziram por muito tempo, a criação de escritas indígenas a partir do sistema alfabético, um tipo de escrita formado por letras, tanto consoantes quanto vogais, como se este sistema fosse adaptável a qualquer tipo de cultura e conteúdo, contradizendo a afirmação do tipógrafo Mandel (2006, p. 11): "a escrita, além da memória da humanidade, é o seu espelho, é a expressão direta do homem e da sociedade". No livro Escritas espelho dos homens e das sociedades, Mandel explica que uma escrita só passa a pertencer a uma sociedade se refletir a imagem de sua cultura e isso só acontece na medida em que os indivíduos se identificam com esta escrita. $\mathrm{O}$ caso do povo norte-americano Cherokee exemplifica a pontuação de Mandel. A comunidade, junto ao seu líder Sequoya, recusou o alfabeto latino, proposto pelos colonizadores europeus, e buscou um sistema de escrita que fosse mais adequado às suas demandas linguísticas e culturais. No século XIX, adotaram como solução o sistema silabário, um tipo de escrita em que as unidades não são as letras e sim as sílabas, para a estruturação da escrita Cherokee. Segundo Ozias (2009), logo após ser inventada, essa escrita foi adotada por toda a comunidade, que se adaptou à tipografia e, rapidamente, começou a utilizá-la para publicar jornais e documentos em sua língua.

A partir do momento em que a introdução e o exercício da escrita se formalizaram nas escolas, o Estado assumiu oficialmente o seu papel na dominação pela escrita. Segundo Emiri; Monserrat (1989), o lugar físico, social e político que tem a escola na aldeia confunde-se facilmente com o lugar que ocupa o Estado para os povos indígenas. As instalações dessas instituições traziam consigo regras, hábitos e estruturas de poder não existentes nas culturas indígenas - como a eleição de monitores e professores, o estabelecimento de horários rígidos, que acabavam condicionando o pensamento indígena e sua organização. Segundo Silva (2002), a antropóloga Lux Vidal faz a seguinte pontuação: "a instituição da educação foi fundamental na configuração dos índios brasileiros, pois da catequese ao positivismo, sempre se quis assimilá-los ao Estado". A aparente motivação de alfabetizar trazia consigo o desejo de controlar. De meio de expressão, a escrita tornou-se uma ferramenta de opressão, um dispositivo de controle.

Com isso, percebe-se que o ensino da escrita pautado na educação foi uma intervenção racional do governo para controlar e bloquear, por meio do saber, as forças indígenas. Durante muito tempo, além de ensinar noções elementares da língua portuguesa (leitura e escrita), as escolas nas aldeias também tornavam os indígenas aptos a cumprirem certos requisitos necessários para sobreviverem na sociedade do "branco", ou seja, transformavam o índio em mão-de-obra qualificada e barata (MELIÀ, 1979). Este cenário de controle ganhou forças em 1910 com a criação do Serviço de Proteção ao Índio (SPI), que colocava os nativos oficialmente sob a tutela do Estado, que assim, passou a atuar de forma mais incisiva para territorializar, civilizar e integrar os povos indígenas na chamada sociedade nacional. Em cada "reserva" indígena foi colocado um posto do SPI e em cada posto uma escola. 


\subsection{Escrita: um instrumento de desefa cultural}

A intenção do Brasil colonial de civilizar e catequizar o indígena foi substituída, no Brasil republicano (até a Constituição de 1988), pela intenção de integrar o indígena na chamada sociedade nacional. Esta mudança só aconteceu devido à pressão que o Brasil sofreu com as denúncias nacionais e internacionais sobre os genocídios e desrespeito cultural para com os povos indígenas. Diante disso, a fim de se evitar intervenções da ONU, em 1967, o governo substituiu o SPI por um novo órgão, a Fundação Nacional do Índio (FUNAI), vigente até hoje. Com o passar do tempo, a ideologia de alfabetizar o nativo, encontrou ecos não esperados nas sociedades indígenas, enquanto o governo queria dominar esses povos por meio da escrita, esses povos queriam dominar a escrita justamente para não serem dominados.

Segundo Markus (2006), foi a partir de 1970 que começaram a aflorar por toda América Latina os movimentos indígenas a favor da preservação de suas identidades e direitos. No Brasil, as articulações, reuniões e assembleias indígenas começam mais sistematicamente a partir de 1974. A partir disso, diversas organizações foram criadas e existem até hoje, como a União das Nações Indígenas (UNI). A Constituição de 1988 reflete os esforços empreendidos pelo movimento indígena e pelas organizações não governamentais que lutavam pela causa indígena, inaugurando um período rico de elaborações e aprovações de leis e normas infraconstitucionais que garantiam às comunidades indígenas o direito à educação escolar básica bilíngue e diferenciada. Determinando ainda, o reconhecimento das características de cada etnia para a elaboração dos conteúdos curriculares e materiais didáticos. Em 1991, foi repassada a responsabilidade sobre a educação escolar indígena, que antes era atribuição da FUNAI, para as Secretarias de Educação dos Estados e Municípios, em sintonia com o Ministério da Educação (MEC).

Atualmente, a escrita se configura mais como uma ferramenta de defesa do que de controle, atuando como guardiã e portadora das vozes e memórias dos povos indígenas do Brasil. Um veículo de comunicação que possibilita, além da preservação e divulgação de suas histórias, adquirir novos conhecimentos para fundamentar suas reivindicações. $O$ indígena, antes visto apenas como um personagem das histórias dos "brancos", tem assumido a voz narrativa, tornando-se sujeito, autor e criador, do seu legado cultural escrito. Deste modo, a nova educação indígena extrapola o simples objetivo de alfabetização, possuindo também outros objetivos: como a transmissão de conhecimentos indígenas; a recuperação de suas memórias e históricas; a reafirmação de suas identidades étnicas; a valorização de suas línguas, tradições e ciências; a publicação de materiais didáticos específicos e diferenciados (LUCIANO, 2006).

\section{OS IMPRESSOS INDÍGENAS}

A história da escrita indígena foi marcada por uma grande fase de opressão, momento em que atuou como um dispositivo de controle do colonizador sobre o colonizado, e por uma fase de libertação, momento em que a comunidade indígena conquistou esse veículo de comunicação a seu favor, resignificando-o como um instrumento de defesa cultural. Foram atos de resistências, fomentados pela necessidade de sobrevivência cultural, de reescrever uma história, e, talvez, de reescrever até mesmo as histórias indígenas, que viabilizaram o surgimento dessa nova face da escrita, que arrancou o poder de voz das mãos dos dominadores. $O$ antigo feitiço da catequese destrutiva virava contra o feiticeiro, o ensino podia ajudar os 
índios na preservação de suas tradições, costumes e fala.

A nova escrita indígena, foi potencializada pela Constituição de 1988 que, além de revolucionar o rumo da política e da educação escolar indígena, estimulou o surgimento dos impressos indígenas, que são tanto os materiais que fazem a transição do âmbito da oralidade para o âmbito da escrita das histórias, cantos, mitos e poesias, conhecidos como "livros da floresta" (ALMEIDA; QUEIROZ, 2004), como os materiais didáticos para alfabetização diferenciada das etnias indígenas do Brasil. Esses impressos, didáticos ou literários, demandam por novos métodos de trabalhos adequados às peculiaridades culturais dos povos indígenas.

Os não indígenas, de diversas áreas (pedagogos, antropólogos, linguistas, designers, sociólogos), envolvidos no novo processo de estruturação da alfabetização indígena e responsáveis pela produção do material didático que circularam nas aldeias, tomaram consciência de que o uso de palavras na língua indígena não poderia ser simplesmente um recurso técnico para facilitar a passagem dos sons às letras e viceversa, já que as palavras dessas línguas são histórias e culturas. Assim, esses profissionais começaram a ter como preocupação fundamental não mais alfabetizar com palavras na língua, mas com palavras da língua. Emiri; Monserrat (1989) afirmam que nas atuais tendências de alfabetização há uma consciência de que toda leitura da palavra é sempre precedida da leitura do mundo que o cerca. Dessa maneira, para a leitura do mundo indígena, o alfabetizador tem que antes se tornar "alfabetizado", aprendendo a respeitar as palavras e o lugar que elas ocupam nesse sistema desconhecido. Segundo Emiri; Monserrat (1989), o resultado do trabalho desenvolvido, com essa nova postura, pela equipe não indígena tem sido extremamente revelador e muito diferenciado dos materiais desenvolvidos pelo SIL, conforme pode se observar na comparação da figura $1 \mathrm{com}$ a figura 2.

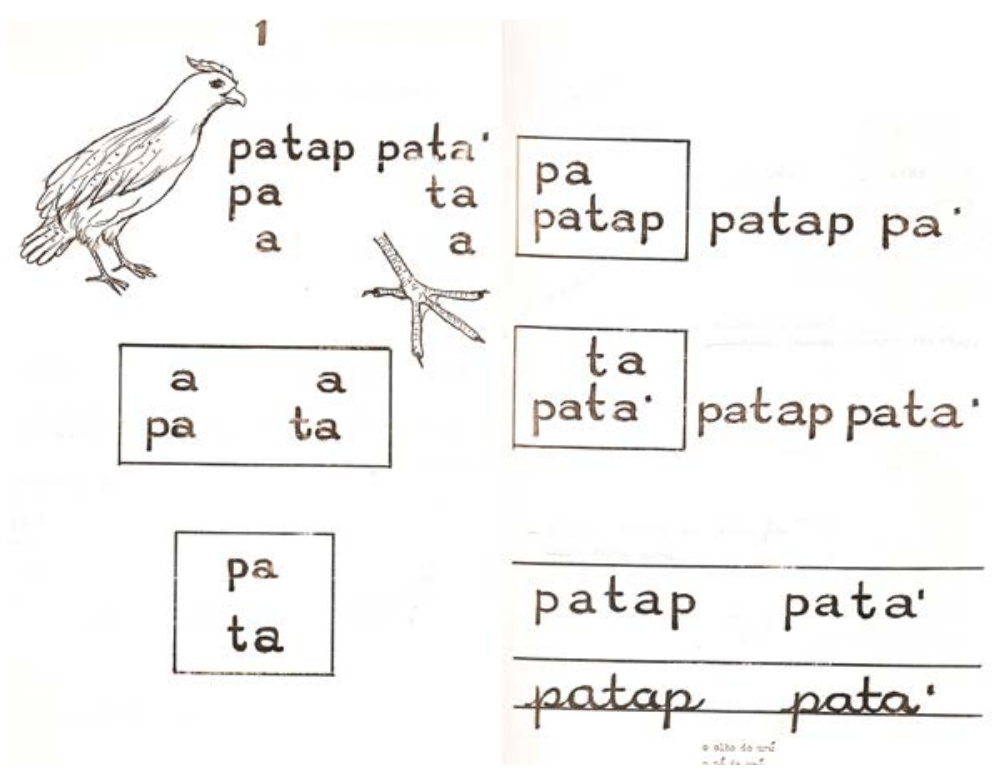

Figura 1: Cartilha de alfabetização Maxakali Patap 1.

Fonte: Harold Popovich; Frances Popovich, 1976. 


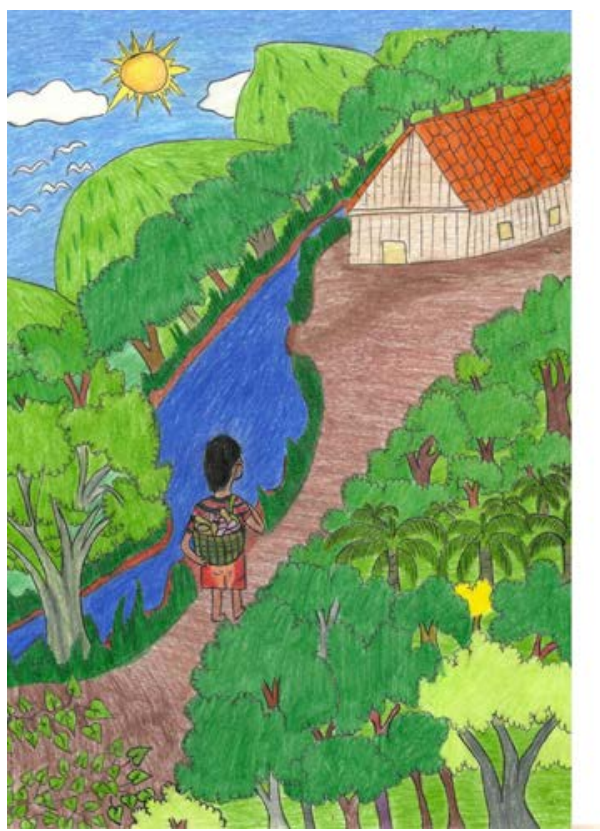

Menino Pataxó,

Tirou batata e foi embora,

Figura 2: Nova proposta de livro de alfabetização do povo Pataxó.

Fonte: Coleção Pega Fruta, 2015, p. 58-59.

Esse novo tipo de material é ilustrado pelos próprios indígenas e acaba por estimular uma forma de arte indígena, que, sem ser tradicional, torna-se um meio privilegiado de comunicação etnográfica, conforme pode se observar na figura 3. Inclusive, a variedade de traços e técnicas sugere a hipótese de uma possível distinção entre estilos visuais entre os povos indígenas, ou seja, assim como as línguas indígenas apresentam estruturas diferentes, existe não apenas uma arte indígena, mas diversas.

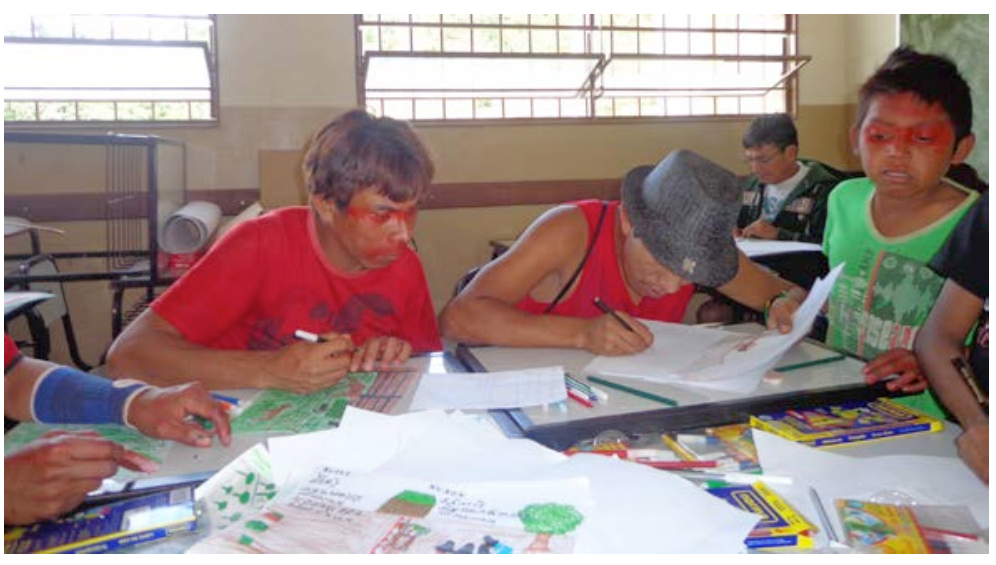

Figura 3: Oficina em Aldeia Verde Maxakali, produção do material $O$ direito a nossa terra. Fonte: Centro de Documentação Eloy Ferreira da Silva - CEDEFES.

As novidades nesses materiais não se limitam apenas ao expressivo uso de ilustrações que, embora sejam muito importantes, fazem parte de um processo de estruturação da alfabetização que deve operar mais com representações do universo da cultura indígena do que com convenções da sociedade não indígena. Dessa maneira, é interessante que nesses materiais haja também partes textuais, expostas numa graduação que vai de conjuntos silábicos mais simples para mais complexos. 0 desafio, nesse processo, é o de se combinar o conteúdo didático com palavras de 
conteúdo cultural relevante. Para isso, o desenho etnográfico contribui de maneira imprescindível, uma vez que abarca um cenário cultural capaz de despertar palavras geradoras. Nestas palavras, é possível detectar sílabas que, por sua vez, expandem-se em família silábicas, geradoras também de outras unidades significativas: palavras, frases, textos (EMIRI; MONSERRAT, 1989). Com isso, as palavras da língua escrita passam a ser conectadas com a língua falada no dia-a-dia do indígena. O sucesso de materiais como esses se deve ao fato de não reproduzirem simplesmente um padrão metodológico ou linguístico, mas por criarem, junto aos indígenas, uma estrutura que respeite, preserve e valorize suas culturas e línguas nativas.

\section{ETNODESIGN}

Segundo Nogueira (2005), grande parte dos designers e dos teóricos do design no Brasil tem seu olhar voltado para as criações dos países industrializados, um gosto pelo que é de fora, havendo uma negligência sobre a cultura material do país. Pouco se discute sobre a cultura material das etnias indígenas, sobre os seus métodos de fazer, construir e criar. Prova disso, segundo Cavalcante (2014), é que mesmo a Organização das Nações Unidas para a Educação, a Ciência e a Cultura (UNESCO) reconhecendo o conhecimento indígena local como parte do patrimônio cultural da humanidade, as formas de expressão indígena registradas no Instituto do Patrimônio Histórico e Artístico Nacional (IPHAN) são insuficientes em relação à quantidade de etnias no Brasil. Como Patrimônio Cultural do Brasil, o IPHAN registrou, até o momento, vinte e nove bens. Desses, somente cinco se referem a culturas indígenas.

O processo de afastamento do design brasileiro para com suas origens culturais e étnicas, muito se deve ao processo de implementação das escolas de design em nosso país, um bom exemplo é o caso o da pioneira Escola Superior de Desenho Industrial (ESDI ), no Rio de Janeiro, com modelo inspirado na escola alemã UIm. Essa base de ensino eurocentrista, foi o grande responsável para que houvesse um afastamento, por parte das escolas de design, por aquilo que pertence culturalmente ao Brasil, elementos importantes para a construção do imaginário do ser brasileiro. Outras áreas do conhecimento, como a Educação, História ou Antropologia, por exemplo, já adotaram métodos de investigação que incluem o saber veiculado no interior das culturas indígenas, partes integrantes da abrangente cultura brasileira. No design, essa interação cultural ainda é bem pequena, segundo Nogueira (2005), na maioria dos cursos de design não há referência às manifestações plásticas indígenas. Privilegia-se, nas escolas brasileiras, o ensino da história da arte pela vertente de todos os "ismos" eminentemente europeus, tais como o cubismo, o impressionismo, o modernismo, etc. Tendo consciência da contribuição dos povos indígenas para à formação da cultura brasileira, sobretudo a contribuição linguística (copacabana, carioca), da culinária (mandioca, pirão, beiju), nos hábitos diários (como do banho), na cultura material (cesto, balaio, rede de dormir), é importante que escolas, professores e pesquisadores em design desenvolvam um maior interesse pelas culturas indígenas que compõe o Brasil.

Diante dessa demanda por um design mais genuinamente brasileiro (CAVALCANTE, 2014), mais as peculiaridades culturais que existem nos processos de comunicação e produção da nova escrita indígena, é que surge o etnodesign. Área de estudo recente no Brasil, que segundo Nogueira (2005), ao se fazer uma busca das variantes da palavra (etnodesign, etno-design, ethnodesign) em sites na internet na 
língua portuguesa, encontra-se pouco mais de cinquenta ocorrências, já os sites em outros idiomas são mais generosos, revelando mais de quinze mil ocorrências. Contudo, uma busca por "design" vai revelar mais de três bilhões de menções ao termo. O etnodesign, segundo Cavalcante (2014, p. 252), surge como um ramo de pesquisa no design que visa possibilitar a revitalização e valorização de elementos e características culturais, de natureza material e imaterial, formadores de uma região, um povo ou uma comunidade.

No Brasil, o etnodesign propõe novas possibilidades para pesquisas em design, sempre em relação com a arte ou a cultura de natureza material e imaterial, o que possibilitará uma compreensão melhor da cosmovisão do mundo ameríndio, universo onde a arte e a vida se confundem, qualquer objeto do cotidiano apresenta em seu design, a associação de diferentes conteúdos utilitário, artístico e simbólico. Percebese assim, que de acordo com a perspectiva ameríndia, as produções materiais e os seres humanos são articulados dentro de um único quadro simbólico de fabricação, de modo que os corpos, as comidas e os artefatos, são produzidos segundo as mesmas técnicas e decorados com os mesmos motivos estéticos, que incorporam e expressam visões do mundo, valores e simbologias particulares.

\footnotetext{
O etnodesign mostra-se interessado não só em investigar e conhecer, mas como portador de um desejo de trocar informações, de perceber e passar esse conhecimento adquirido nas escolas de design. Trazer para os cursos de design esse aprendizado e levar deles ideias, propostas de inovações que possam melhorar a qualidade de vida de outras culturas (NOGUEIRA, 2005, p. 36).
}

Por esse viés, o design poderá se aproximar da antropologia simbólica e da antropologia estética, em um consistente trabalho de reconhecimento e identificação da cultura material e imaterial que contribui para definir a identidade cultural brasileira. Em uma perspectiva transdisciplinar, o olhar do designer pode revelar descobertas, no tocante ao resgate de saberes e tecnologias, no tangente a interpretações do universo simbólico das etnias do Brasil, no reencontro e na valorização do "fazer com as mãos". Para tanto, o processo de investigação etnográfica ${ }^{1}$ tem que começar a fazer parte do universo acadêmico do design no Brasil, tornando-se uma ferramenta capaz de contribuir com a construção da identidade do design brasileiro.

\section{CONCLUSÃO}

A educação escolar, na percepção dos povos indígenas, além de ser um direito básico, é estratégica na construção de seus projetos societários de futuro. Por isso, aumentou, nos últimos anos, a demanda por implantação de educação escolar nas terras indígenas. Segundo Luciano (2006), vinte anos atrás, o número de professores indígenas não ultrapassava a marca de $20 \%$ do total dos docentes que trabalhavam nas

\footnotetext{
${ }^{1}$ Segundo CAVALCANTE (2014, p. 144), a etnografia envolve experimentação, uma procura de múltiplas fontes de informações, dados e evidências para se alcançar diferentes perspectivas por meio da observação participante e registros em diário de campo. Na maioria das vezes, é equacionada com uma imersão mais profunda do pesquisador dentro da cultura, grupo ou comunidade sendo estudada.
} 
escolas implantadas em comunidades indígenas. Atualmente, os professores indígenas presentes nas escolas indígenas representam mais de $96 \%$ dos mais de 12 mil em atividade e os povos indígenas se apresentam, hoje, como um dos segmentos da sociedade brasileira que luta com maior intensidade pelo acesso à escola pública. Diante dessa movimentação social, que potencializa a nova escrita indígena, e da demanda crescente, por parte dos indígenas, por material impresso, sobretudo livros, vislumbram-se várias possibilidades de produção e experimentação de projetos na área do design.

É inegável, que o trabalho com povos que têm se revelado altamente complexos em seus sistemas sociocosmológicos, exige caminhos diferentes dos convencionalmente utilizados pelos não indígenas ou pela academia. Assim, na área do design, o etnodesign apresenta-se como um desses novos caminhos, capaz de permitir a revitalização e valorização de saberes e técnicas, tornando-se um instrumento importante para a consolidação da identidade nacional e para a construção de um design genuinamente brasileiro, rico em cultura e identidade (CAVALCANTE, 2014). Em pesquisas de etnodesign, não cabe ao designer questionar a pertinência da escolha da escrita alfabética, já adotada pelos diversos grupos indígenas para representação de suas línguas no Brasil, nem interferir no conteúdo de suas publicações, mas sim entender a troca cultural a que os índios estão expostos e dispostos. O designer deve ser um bom observador e permanecer atento à sabedoria e riqueza cultural dessas comunidades para conseguir selecionar e adaptar os instrumentos gráficos às reivindicações dos povos indígenas.

\footnotetext{
Tomar a produção desses povos como material didático, onde o etno, o tecno e o imagético podem ser lidos como uma multiplicidade de modos de fazer, de atuar socialmente através de categorias comunicativas, é apostar na construção de um tipo de instrumento metodológico que permite às populações indígenas desenvolver estratégias de atuações, frente às denúncias contra violações dos seus direitos, bem como promove articulações de apoio entre os povos. Estas práticas apropriam-se e reinventam os modelos eurocêntricos de escrita em diferentes momentos e espaços de educação tradicional dos povos indígenas (CESAR; SOUZA; COSTA; 2012, p. 21).
}

Para o design, trabalhos embasados no etnodesign poderão se desprender de uma visão internacionalizada, sobretudo a europeizada e a americanizada, que estão focadas somente nos países industrializados e no que eles produzem, sendo capaz assim de reduzir as fronteiras interétnicas no meio cultural e social em que o design está inserido. Acredita-se ainda, que os ensinamentos do etnodesign podem ser aplicados em projetos culturais que, através de políticas públicas, podem viabilizar o acesso de diversas pessoas à cultura indígena.

\section{REFERÊNCIAS}

ALMEIDA, Maria Inês; QUEIROZ, Sônia. Na captura da voz: as edições da narrativa oral no Brasil. Belo Horizonte: Autêntica, 2004.

CAVALCANTE, Ana Luisa. Design para a sustentabilidade cultural: recursos estruturantes para sistema habilitante de revitalização de conhecimento local e indígena. 2014. 321 f. Tese - Universidade Federal de Santa Catarina, Programa de Pós- 
Graduação em Engenharia e Gestão do Conhecimento, Florianópolis.

CESAR, América; SOUZA, Arissana; COSTA, Suzane. Para uma cartografia da Educação Escola Indígena. Linguagens, identidades e letramentos. vol. 2. n. 2. 2012. Disponível na internet por http em: <http://www.poscritica.uneb.br/revistaponti/arquivos/ volume2-n2/4.PARA-UMA-CARTOGRAFIA-DA-EDUCACAO-revistaponti-vol2-n2.pdf>. Acessado em 20 fev. 2016.

EMIRI, Loretta; MONSERRAT, Ruth. A Conquista da Escrita - Encontros de Educação Indígena. São Paulo: Iluminuras, 1989.

LIMA, Amanda. O livro indígena e suas múltiplas grafias. 2012. 155 f. Dissertação Faculdade de Letras da Universidade Federal de Minas Gerais, Belo Horizonte.

LIMA, Antonio. Um grande cerco de paz: poder tutelar, indianidade e formação do Estado no Brasil. Petrópolis, Rio de Janeiro: Vozes, 1995.

LUCIANO, Gersem. O Índio Brasileiro: o que você precisa saber sobre os povos indígenas no Brasil de hoje. 2006. 236 f. SECAD/MEC, Brasília. Disponível na internet por http em: <http://www.trilhasdeconhecimentos.etc.br/livros/arquivos/ColET12_ Vias01WEB.pdf>. Acessado em 28 set. 2014.

MANDEL, Ladislas. Escritas - espelho dos homens e das sociedades. São Paulo: Rosari, 2006.

MARTINS, Josenei. Caderno de Estudos: Didática e Educação. Centro Universitário Leonardo da Vinci. Indaial: Uniasselvi, 2009.

MARKUS, Cledes. Identidade étnica e educação escolar indígena. 2006. $59 \mathrm{f}$. Dissertação - Universidade Regional de Blumenau, Centro de Ciências da Educação.

MELIÀ, Bartolomeu. Educação indígena e alfabetização. São Paulo: Loyola, 1979.

NOGUEIRA, José. Etnodesign: um estudo do grafismo das cestarias dos M’byá guarani de Paraty-Mirim. 2005. 130f. Dissertação - Pontifícia Universidade Católica do Rio de Janeiro.

OZIAS, Alves. A história de um índio analfabeto que inventou uma escrita. 2009. Disponível na internet por http em: <http://oziasjornalismo.blogspot.com.br/2009/09 /historia-de-um-indio-analfabeto-que.html>. Acessado em 1 nov. 2015.

PLAZA, Julio. Tradução Intersemiótica. São Paulo: Perspectiva, 2003.

RODRIGUES, Aryon. Línguas Brasileiras: para o conhecimento das línguas indígenas. São Paulo: Loyola, 1986.

SILVA, Aracy. Quando aprender é programa de índio. Antropologia, história e educação. Disponível na internet por http em: <http://revistapesquisa.fapesp.br/wp content/uploads/2002/10/82ensino.pdf?3414f4>. Acessado em 15 nov. 2015. 